\title{
O PROCESSO dE ORGANIZAÇÃo dA INSTRUÇÃo PÚBLICA PATENSE NO CONTEXTO REPUBLICANO DE 1892-1928
}

\author{
THE PROCESS OF ORGANIZATION OF PUBLIC INSTRUCTION IN CONTEXT \\ PATENSE REPUBLICAN 1892-1928
}

Andréa Fabiane Machado Diniz ${ }^{1}$

\begin{abstract}
RESUMO: Apresenta um estudo teórico e documental com o objetivo de compreender o processo de organização da Instrução Pública em Patos de Minas/MG no contexto republicano de 1889 a 1928. As fontes utilizadas para esta pesquisa são: jornais, legislações educacionais, termos de visita dos inspetores de ensino de época, atas da Câmara Municipal, atos do Executivo e correspondências trocadas entre diretores, inspetores e governo. Os jornais selecionados para análise foram: O Trabalho, O Commercio e Cidade de Patos. A idealização e a materialização da instrução pública, ministrada nos Grupos Escolares, era, na concepção dos republicanos, o instrumento eficiente para formar o cidadão e elevar o País à condição de nação civilizada. Dessa forma, à educação era confiada a nobre missão de formar o homem urbanizado, civilizado e, principalmente, capaz de se adequar às novas regras de uma sociedade que buscava se alicerçar nos pilares do trabalho e da ordem pública.
\end{abstract}

Palavras-chave: Primeira República. Instrução Pública. Grupo Escolar. Patos de Minas.

\begin{abstract}
Presents a theoretical study and documentation in order to understand the process of organization of Public Instruction in Patos de Minas / MG in the context Republican from 1889 to 1928 . The sources used for this research are: newspapers, educational legislation, terms of inspectors visiting teaching time, the minutes of the City Council, executive orders and correspondence exchanged between principals, inspectors and government. The newspapers selected for analysis were: O Trabalho and O Commercio e Cidade de Patos The idealization and materialization of public instruction, taught in School Groups, was, in the design of Republicans, efficient tool to form the citizen and elevate the country to the status of a civilized nation. Thus, education was entrusted with the noble mission of forming man urbanized, civilized, and especially able to adapt to the new rules of a society that sought to build on the pillars of work and public order.
\end{abstract}

Keywords: First Republic. Public Instruction. School Group. Patos de Minas.

\footnotetext{
1 Mestre em Educação pela Universidade de Uberaba - UNIUBE/MG. Analista educacional da Superintendência Regional de Ensino de Patos de Minas/MG.
} 
Implica a consciência de que, como toda pesquisa, a investigação histórica não é desinteressada. Consequentemente, o que provoca o impulso investigativo é a necessidade de responder a alguma questão que nos interpela na realidade presente [...]não posso compreender radicalmente o presente se não compreender as suas raízes, o que implica o estudo de sua gênese. ${ }^{2}$

Dermival Saviani

\section{Considerações iniciais acerca da pesquisa e do contexto histórico}

Na perspectiva de considerar a educação como fonte de inesgotável investigação e preocupação essencial do Brasil e do mundo, torna-se indispensável o aprofundamento de estudos teórico-práticos para entender os fios e as tramas da tessitura dos saberes construída em cada contexto histórico. Assim, esse artigo resulta de uma pesquisa desenvolvida no Programa de Mestrado em Educação da Universidade de Uberaba- UNIUBE e representa um estudo teórico e documental no campo da história da educação com o objetivo geral de compreender como se desenvolveu o processo de organização da instrução pública no município de Patos de Minas (MG) 3 no contexto republicano de 1892 a 1928. A compreensão da história da educação nacional, estadual e regional, torna-se importante para se compreender com maior eficiência o desenvolver da educação local. A tendência de se realizar estudos mais localizados tem possibilitado:

Um aprofundamento de certos temas e uma complexificação na compreensão do passado de determinados fenômenos educativos que, anteriormente, eram visualizados apenas panoramicamente. Tem sido comum, por exemplo, no Brasil, que os pesquisadores de diversos estados procurem compreender determinados movimentos educacionais naquela realidade específica. Isso tem provocado uma verdadeira revisão daquilo que antes se tinha como verdade para todo o País e que, muitas vezes, só servia para compreender a

\footnotetext{
2 SAVIANI, D. História das ideias pedagógicas no Brasil. Campinas: Autores Associados 2007, p. 4.

3 Os memorialistas Geraldo Fonseca (1959 e1974) e Oliveira Mello (1971 e 2008) relatam que o casal Antônio Joaquim da Silva Guerra e Luiza Corrêa de Andrade doou terras em 1826 para Santo Antônio com o objetivo de construir um templo e, sobretudo, acomodar os povos que cortavam essas estradas rumo a Paracatu em busca de minas de ouro. A partir de então, originou-se o Arraial de Santo Antônio da Beira do Paranaíba. Passados os anos, houve a criação da vila, em 1866, e, em 1868, sua instalação. A vila foi elevada à categoria de cidade em 24 de maio de 1892, pelo presidente do Estado de Minas Gerais.
} 
realidade de São Paulo ou do antigo Distrito Federal, por exemplo. Muitas vezes, estudos realizados em alguns locais que, contemporaneamente, são mais fortes econômica e politicamente, generaliza (va) $\mathrm{m}$ as suas conclusões para a realidade do País em sua totalidade [...]. Generaliza (va)-se para o país o que é (era) específico somente para uma parte dele. (LOPES; GALVÃO, 2001, p. 41-42)

Fundamentado nesse pressuposto, elegemos Patos de Minas como perspectiva de abordagem para a história da educação na dimensão local. Assim, esse estudo se constrói sem perder de vista o diálogo de natureza maior, a história da educação no âmbito nacional.

A pesquisa desenvolvida constitui parte do projeto "A organização da Instrução Pública nas cidades de Uberabinha e Patos de Minas: educação e civilização (1888-1930)", desenvolvida por um grupo de pesquisadores na área da História da Educação Brasileira, coordenado pela professora Dra. Luciana Beatriz de Oliveira Bar de Carvalho e financiado pela MCTI/CNPq/MEC/CAPES No 07/2011. No que se refere ao estudo da história da educação na região do Alto Paranaíba, em especial no munícipio de Patos de Minas, de forma sistematicamente organizada, é uma manifestação recente, data de 1993, com a implantação do projeto de "Levantamento e Catalogação das Fontes Primárias e Secundárias de Interesse para a História da Educação Brasileira e do Triângulo Mineiro e Alto Paranaíba", ligado a uma proposta nacional estruturada a partir da Faculdade de Educação da Universidade de Campinas-UNICAMP, sob a coordenação geral do professor Dr. Dermeval Saviani. Trabalho esse realizado até fins de 1996, e, a partir de 1997, iniciaram-se: "estudos voltados para temáticas histórico-educacionais singulares, tais como os voltados para a história das instituições escolares, para a notícia educacional veiculada por jornais e revistas e para a história das disciplinas escolares" (ARAÚJO, 2002, p. 11).

Por se tratar de uma pesquisa voltada para a temática históricoeducacional, a delimitação do período de estudos é indispensável. Desse modo, o marco inicial estabelecido foi o ano de 1889, com a proclamação da República, acontecimento histórico que marcou a transição entre as formas de governos da Monarquia para a República, período esse em que os novos governantes não só se colocaram na condição de inauguradores de uma ordem política superior em oposição ao Império, mas também na situação daqueles que se propõem a 
reorganizar a própria nação brasileira, instituindo novos valores, símbolos cívicos, heróis, leis, etc. O marco final é o ano de 1928 - ano de publicação dos últimos decretos que criaram a reforma educacional Francisco Campos durante o governo de Antônio Carlos de Andrada em Minas Gerais. Nesse recorte temporal, a educação se apresentava, na maioria das vezes, como a redenção de uma nação marcada pelo analfabetismo, pelo atraso técnico, pela base econômica e política de origem rural, sendo necessária sua organização de forma rápida, porém eficiente. Para consolidar essa sociedade diferenciada proposta pela República, seria imprescindível a formação de um novo cidadão, responsável pela nova ordem, respeitando as normas e trabalhando para o engrandecimento do país.

A nova forma republicana, ao mesmo tempo em que trazia avanços, gerava também dificuldade para conviver com a alternância de poderes. Essa rotatividade implicava em sucessivas legislações e reformas educacionais na tentativa de melhor organizar a instrução pública, visto que a educação não poderia se desenvolver espontaneamente; era necessário direcionamento e controle sobre a ação dessa instituição redentora.

Nessa euforia, por civilizar a sociedade e formar o novo cidadão da e para a República, a via considerada mais eficiente e que promoveria uma instrução quase que em "massa" foi materializada com a instituição dos Grupos Escolares. Esses estabelecimentos se constituíram em espaços destinados exclusivamente para a instrução, sendo considerados os verdadeiros 'templos do saber'4 Foi esse clima de calorosos debates e entusiasmo pela tão nobre missão destinada à instrução pública que envolveu, logo nos primeiros anos do século XX, a "elite" 5 política patense, na ocasião formada por "coronéis", "doutores", "majores", nas discussões e convicções disseminadas pela República. Essa "elite" desejava para Patos de Minas os louros da urbanidade, da civilidade, da modernidade e do progresso, aspectos reiteradamente devotados pelos discursos republicanos. Em

4 Cf. SOUSA, Rosa Fátima 1998. Verbete sobre Grupos Escolares disponível em http://www.histedbr.fae.unicamp.br/navegando/glossario/verb c grupo \%20escolar.htm

$5 \frac{0}{O}$ conceito de elite usado neste estudo refere-se a "[...] grupos funcionais, sobretudo ocupacionais, que possuem status elevado (por uma razão qualquer) em uma sociedade". BOTTOMORE, T. B. As elites e a sociedade. Rio de Janeiro: Zahar, 1965, p.15. Em Patos de Minas, a elite incluiria não apenas a classe dominante em termos econômicos e políticos, mas também jornalistas, professores e intelectuais em geral etc. 
se tratando de instrução no município de Patos de Minas, em 1853, foi baixada pelo governo da Província uma portaria criando uma cadeira de instrução primária na Freguesia de Santo Antônio dos Patos, mas tal atitude não foi suficiente para resolver o problema da instrução, ou melhor, da falta de instrução (FONSECA, 1974). Quanto às discussões decorrentes da centralização ou descentralização do ensino, a falta de orientação nacional com relação aos procedimentos instrucionais e à ausência de determinações específicas para a instrução primária na Constituição Federal de 1891 disseminava insegurança em relação ao conteúdo das propostas estaduais de reforma, o que acarretaria, provavelmente, heterogeneidade de resultados.

Essa questão do envolvimento do município nas coisas da instrução aparece como reflexo da transmissão aos estados da responsabilidade pela instrução pública popular. Decorridos três anos pós-proclamação da República, e um ano pós-publicação da Constituição Federal Republicana de 1891, em Minas Gerais surgiu a Lei no 41 de 03 de agosto de 1892, também conhecida por Reforma Afonso Penna, cuja finalidade era reformar a instrução pública em seus diversos níveis. Nessa Reforma, é possível perceber a preocupação do legislador com a descentralização do ensino, pois "o 'Conselho Superior' então criado era um órgão central que, não obstante, não interferia em muitos detalhes da administração escolar que era de competência regional ou local" (MOURÃo, 1892, p. 25). Desse modo, pode-se inferir que a responsabilidade pelo encaminhamento da instrução pública encontrava-se também destinada às administrações municipais. No entanto, apesar de existirem as legislações estaduais, os municípios também podem estabelecer o seu corpus legislativo, contendo os princípios e as regras de funcionamento do ensino tendo em vista as características peculiares de cada localidade.

Buscando alcançar o objetivo proposto realizamos um estudo historiográfico, utilizando a revisão da literatura especializada e a pesquisa documental. Na concepção de André Cellard (2008), respaldamos o uso da terminologia pesquisa documental. Em se tratando de "pesquisa documental, o trabalho do pesquisador (a) requer uma análise mais cuidadosa, visto que os documentos não passaram antes por nenhum tratamento científico" (oliveira. 2007, p. 70). Quanto aos estudos historiográficos estão fundamentados na 
corrente de pensamento da Escola de Annales. Os presságios dessa nova forma de se fazer História afirmam que "toda fonte histórica exprime o poder da sociedade do passado sobre a memória e o futuro" (LE GOFF, 1996, P. 10). Nessa perspectiva, o acontecer histórico se faz

[...] a partir dos homens. Daí o documento histórico se produzir com tudo o que, pertencendo ao homem, depende do homem, exprime o homem, demonstra a presença, a atividade, os gostos e as maneiras de ser do homem. Nesse caso, ao documento incorporam-se outros de natureza diversa, tais como objetos, signos, paisagens, etc. (VIEIRA, 1995, p. p. 14-15)

Para a narrativa histórica, configurada nessa visão, não interessa somente os grandes feitos dos grandes homens ou heróis, tão valorizados pela historiografia tradicional, mas interessa, sobretudo, os elementos de bastidores que são pouco explorados, como, por exemplo, pais, crianças, professores, etc. É nesse rastro, nessa nova forma de historiar a educação, que essa pesquisa buscou a compreensão do processo de organização da instrução pública patense em tempos de Primeira República.

No processo de (re) constituir o passado, os documentos devem ser analisados e entendidos dentro do contexto específico de interação. As fontes utilizadas compõem-se de livros e artigos que versam sobre a Primeira República, e a base de dados utilizada para pesquisa documental, armazenada no Arquivo Público Mineiro em Belo Horizonte, Arquivo Municipal, no Patrimônio Histórico de Patos de Minas e na Escola Estadual Marcolino de Barros, é composta por fotos, jornais, legislações educacionais, termos de visita dos inspetores de ensino, atas da Câmara Municipal e Atos do Executivo. Os jornais analisados foram: O Trabalho, O Commercio e Cidade de Patos. Iniciamos a pesquisa nos jornais patenses a partir do ano de 1905, pois em período anterior a essa data, não havia periódicos de produção própria do município ${ }^{6}$. A circulação iniciou-se com o jornal "O Trabalho", que teve a primeira publicação em 1905.

Em termos de imprensa jornalística, Patos de Minas se mostra relevante. Havia, no contexto republicano, vários periódicos em circulação e os artigos

\footnotetext{
${ }^{6}$ Cf. também MATOS, M. H. R. de. Educação e imprensa em palcos republicanos: análise dos jornais de Patos de Minas/MG (1889-130). Dissertação de (Mestrado em Educação). Faculdade de Educação, da Universidade de Uberlândia/UFU, Uberlândia, 2009.
} 
neles veiculados constituem valiosa fonte para a recuperação da história e dos caminhos trilhados pela educação patense, pois

a imprensa, especializada ou não, em muito contribuiu para se historiar as pistas deixadas pelo pensamento educacional ao longo deste século no Brasil e, em especial, na região do Triângulo Mineiro, pois nos permitiu encontrar um cabedal enorme de informações das mais variadas formas do pensamento pedagógico. (CARVALHO, 2004, p. 57)

Os jornais apesar de trazerem visão momentânea de um determinado acontecimento, nos permitem acompanhar seu percurso por meio de múltiplas informações compiladas e cronologicamente organizadas. Portanto, essa fonte se torna valiosa para o investigador na medida em que

\begin{abstract}
condensam toda uma informação, dispersa e esquecida, em milhares e milhares de páginas publicadas ao longo do período que escolhemos. Informação que, em muitos casos, não se encontra em outras fontes a que recorre o historiador. Justifica-se, pois, inteiramente a vantagem em dispor de um instrumento que facilite a pesquisa, tornando as fontes mais acessíveis numa ordem temática e cronológica. (ADÃO; MATOS, 2004, p. 61)
\end{abstract}

A imprensa de cunho jornalístico veicula a opinião de vários sujeitos envolvidos no processo permitindo que um fato seja compreendido por vários vieses. Desse modo, interessa-nos compreender como os assuntos inerentes ao campo da educação e do pensamento pedagógico eram abordados nos discursos dos articulistas dos jornais de Patos de Minas. Nessa análise, não desconsideramos, em momento algum, a probabilidade de a imprensa, ao mesmo tempo em que exercer a função de representante de uma visão de mundo e testemunhar acontecimentos educacionais, ser também um instrumento para disseminação e legitimação das ideias da política dominante.

A partir do estudo dessas fontes, pudemos entender que cada período histórico, seja em um país, em um estado ou em uma região, deixa como herança para a posteridade algumas categorias com as quais as elites tentam difundir sua ideologia e, às vezes, aquelas com as quais os setores dominados procuram - nem sempre conseguindo - resistir à manipulação. Pudemos entender também alguns aspectos que os setores dominantes montam, 
convencem/impõem ao restante da população, em torno das quais procuram justificar suas atitudes. Esse manancial de fontes permitiu a articulação entre o contexto social, político, econômico e cultural, local e nacional, vivenciado durante a República Velha.

\title{
Desenvolvimento
}

\section{O processo de organização da instrução pública através do Grupo Escolar: ações da "elite" e da imprensa local}

Registra-se na história educacional da cidade logo nos primeiros anos do século XX, em 1907, a instalação:

\begin{abstract}
[...] da escola do sexo masculino desta cidade regida pelo Professor Normalista Modesto de Mello Ribeiro, na qual matricularam-se 69 alumnos, comparecendo 58 destes. Esse acto, que foi presidido pelo Inspector Escolar Capm. Aurelio Theodoro de Mendonça revestiu-se de grande solenidade, concorrendo para isso a presença de diversos cavalheiros de nossa melhor sociedade, da filarmônica 'S. Cecilia' e do representante desta folha gentilmente convidado para esse fim [...]. Orou em seguida o venerando Vigario desta parochia, Ver. Pe. Getulio Alves de Mello que igualmente se dirigiu às creanças falando-Ihes sobre o respeito devido aos paes, aos mestres e as pessoas mais velhas [...] concluio congratulando-se com os presentes pela instalação da escola sendo muito aplaudido. 0 professor da cadeira convidou os alumnos a comparecerem no dia seguinte para se começar os trabalhos do presente anno lectivo e terminou-se naquela festa escolar que nos deixou as mais gratas impressões (O TRABALHO, 1907, n. 11, p. 01).
\end{abstract}

Os momentos festivos e dedicados a inauguração de grandes ações também serviam de oportunidades para que os convidados ilustres disseminassem as simbologias que envolviam a República como pode ser perceptível no discurso proferido por Marcolino Ferreira de Barros ${ }^{7}$, na ocasião de inauguração de uma escola de ensino primário na cidade:

\footnotetext{
7 Baiano, natural de Jaguari, a noroeste de Salvador. Chegou a Patos de Minas em 1895; bacharel em Direito pela Faculdade de Recife e veio para Patos com a nomeação de juiz municipal da Comarca de Patos. Ocupou a vice-presidência do Partido Republicano, foi presidente da Câmara Municipal e eleito prefeito por três ocasiões e ainda deputado federal pelo Estado da Bahia de 1923 a 1927, faleceu em 24/05/1932, sua esposa Julieta Maciel era filha do coronel Antônio Dias
} 
[...] usou da palavra com a eloquência que the é peculiar, o ilustrado advogado Dr. Marcolino de Ferreira de Barros o qual começou agradecendo em nome do Professor a todos que ali se achavam para assistir a instalação da escola e, dirigindo-se depois aos alumnos, aconselhou-Ihes a maior assiduidade e dedicação aos trabalhos escolares; evidenciou a necessidade da instrucção, afirmou ser esta a verdadeira base da felicidade humana. 'O livro disse elle- é o nosso melhor amigo; não há pezar que não se mitigue com a leitura de um bom livro'. Ao terminar sua brilhante oração foi muito felicitado, executando então a banda de musica que se achava postada ao fundo do salão, o hynno nacional que foi ouvido de pé. (TRABALHO, 1907, n. 11, p. 01)

Diante do passar dos anos, do processo de estruturação da cidade e do aumento da população a necessidade de escolarização era cada vez mais proeminente para alavancar o progresso, concepção responsável por mover muitas ações nos municípios interioranos. Em Patos de Minas desde sua elevação à categoria de cidade em 1892 esforços foram engendrados para intensificar a vida política local, promover melhorias na cidade e na rudimentar instrução pública, visando sua inserção nos trilhos da modernidade e do progresso, pensamento imperativo e bastante devotado em época de Primeira República.

A organização da instrução pública primária traduzida na ampliação do saber harmonizada com os princípios da ordem e do progresso constituiu premissa relevante no projeto de modernização que a República almejava materializar na sociedade brasileira e entre reflexões e ações empreendidas em prol da educação, progredir supunha relação direta com a escolarização da população. Essa também era a concepção que movia as ações dos intelectuais e da edilidade patense para a cidade dispor de um local próprio e com identidade para o estabelecimento do ensino, no caso um Grupo Escolar, sendo sua instalação a expressão da consolidação do ideário republicano e a inserção da cidade na roda do desenvolvimento. Quando proposto a criação dos Grupos Escolares por João Pinheiro como sendo os novos rumos para a educação, a proposta foi logo acolhida pela "elite" local.

De todos os recantos da patria mineira irrompem expontaneos, os mais francos encomios ao governo pela energia e particular attenção com que se dedica a este importantissimo ramo da

Maciel. DIMEP-Diretoria de Memória e Patrimônio de Patos de Minas. MuP- Museu da cidade de Patos de Minas 
administração publica. Diversas camaras municipaes procuram secundar a acção do governo offerecendo-Ihe predios destinados á installação de grupos escolares, concorrendo assim para a diffusão do ensino. (O TRABALHO, 1906, n. 4, p. 01)

Uma possibilidade de melhoramento já era avistada, pois, João Pinheiro teria tomado medida concreta em relação ao assunto. Desse modo, era nítido "um certo enthusiasmo, um novo sopro de vida, de fé, em nosso povo, que parece despertar de sua apathia culpável, de sua indiferença criminosa" (O TRABALHO, 1906, n. 4, p. 01). Apesar de a matéria afirmar que várias edilidades municipais já estavam interessadas na criação dos Grupos Escolares, no interior ações foram mais tardias e esses estabelecimentos chegaram alguns anos depois, como é o de Patos de Minas que teve seu primeiro Grupo Escolar instalado em 1917.

Se num primeiro momento a matéria do Jornal "O Trabalho" em clima de euforia e esperanças enaltecia o empenho do governo mineiro em defesa da instrução pública, num segundo momento atestava que os homens públicos que compunham a edilidade de época, não mediariam esforços para instalar essa instituição como condição importante de melhoramento para Patos de Minas. Discorre a matéria do citado jornal:

Folgamos de consignar aqui e tambem a nossa edilidade emprega todos os esforços para dotar esta cidade com este importante melhoramento. Acreditamos que a creação desses grupos vem operar uma verdadeira transformação no ensino, tornando-o uma realidade. Não nos devemos deter portanto ante sacrificio algum para a consecução desse desideratum [...].(O TRABALHO, 1906, n. 4, p. 01).

Perante a esse fato, algumas providências se fizeram necessárias para que ocorresse a instalação do tão sonhado Grupo Escolar, a título de exemplificação citamos: a realização do levantamento das crianças em idade escolar, e a principal tarefa, conseguir um local para se construir o prédio. Nessa incursão e considerando tais critérios, coube ao médico e examinador de escolas, Dr. Laudelino Gomes de Almeida, encaminhar solicitação em 1907 para Manuel Tomaz de Carvalho Brito, então Secretário do Interior, requisitando para Patos 
de Minas um Grupo Escolar. Nessa solicitação Dr. Laudelino demonstra consciência dos percursos educacionais que o País estava trilhando e atesta:

\begin{abstract}
Conhecedor de perto do processo adotado em São Paulo e no Rio de Janeiro, do modo por que se faz a educação da criança, vim de molde lembra a V. Excia. Alvitre que não deve ser desprezado em benefício da infância, que, mal cuidada perderá o precioso tempo, consumindo em simulacros de instrução, crescendo verdadeiros analfabetos. Todo o rigor, o maior zelo, encendrado amor ao cumprimento do dever garantem o resultado a que procura chegar V. Excia [...] levo ao seu conhecimento o resultado de minhas impressões, depois de ter penetrado na qualidade de examinador, convidado pelo ilustre inspetor escolar municipal, cidadão Capitão Aurélio Theodoro de Mendonça, nas três escolas aqui existentes, sendo duas do sexo masculino e uma do sexo feminino. [...] $\mathrm{Na}$ primeira cadeira a cargo do professor Modesto de Mello Ribeiro, encontrei muita ordem e adiantamento por parte dos alunos, ensinados de acordo com o programa [...] a $2^{a}$ cadeira do sexo masculino e a $3^{a}$ do sexo feminino, pois, nada tenho a dizer de modo a abonar o que foi dado observar, com o exame de cada aluno: o método é primitivo e o aproveitamento nulo, aí o programa foi posto inteiramente à margem [...]. (FONSECA, 1974, p. 160-161)
\end{abstract}

Essas afirmações contidas no documento do Dr. Laudelino abordavam a ineficiência do ensino ministrado em Patos de Minas, a partir de três pontos cruciais: ausência de uniformidade do material didático, método primitivo e professores mal preparados. Nesse sentido, era esperado que o Grupo Escolar trouxesse mudanças substanciais para a escolarização. Portanto, tais considerações serviram como contextualização e fundamentação para afirmar que "o nosso meio comporta um grupo escolar. Autoriza-me a assim pensar um número avultado de crianças, número superior a 200 crianças de ambos os sexos [...] esta é uma cidade que se vai desenvolvendo a olhos vistos." (FONSECA, 1974, p. 160).

Pelo documento do Dr. Laudelino é perceptível que a cidade estava em processo de crescimento e desenvolvimento sendo necessário alargar os passos rumo ao progresso. A autorização para a instalação do grupo escolar certamente contribuiria para esse desenvolvimento e para a civilidade, ideal republicano fortalecido nas mentes da "elite" patense. O pedido para a construção do Grupo foi efetivado em 1907, mas sua criação ocorreu somente em 1913 através do Decreto 4065 de 23 de dezembro e a instalação foi concretizada somente em 04 de junho de 1917, quatro anos posterior à sua criação. Nos anos pós-pedido de 
criação desse grupo escolar, a imprensa de Patos de Minas não se furtou de registrar a importância para a instrução pública e dos esforços envidados para sua efetivação. Pode ser lido no Jornal "O Trabalho" no que concerne às ações empreendidas pelo Dr. Laudelino que:

[...] auxiliado pelo Cel. Farnese Dias Maciel e pelo provento professor Modesto de Mello Ribeiro shaiu a campo colhendo assignaturas para a construcção do Grupo Escolar na nossa cidade, encontrando o melhor acolhimento por parte de todos a que se têm dirigido em busca do auxílio que será a base para que o magestoso se erga na nossa cidade e o edifício que registrará o marco do nosso devotamento a causa da instrucção do povo em todas as suas classes, base essencial, para o nosso progresso material e intellectual, freio irresistível à corrupção dos costumes que a Deus dará, se vão pervertendo do berço a velhice. ( $O$ TRABALHO, 1908, n. 62, p. 01-02)

Além dessas ações o Dr. Laudelino fez doações em dinheiro para colaborar com a construção do prédio destinado ao Grupo Escolar, conforme consta registrado pela Câmara Municipal:

[...] Cornélio França d'Oliveira por parte da Comissão de Legislação apresentou parecer sobre o officio do Senhor Dr. Laudelino Gomes de Almeida; aceitando a doação da quantia de tresentos mil réis $(300 \$ 000)$ que o mesmo senhor faz a Câmara Municipal, como condição de ser a referida importância applicada como auxilio a construção de uma casa para o grupo escolar desta Cidade. (ATA DA SEXTA SESSÃO ORDINÁRIA, 1909, s/d)

A cidade de Patos de Minas procurava integrar-se no movimento de modernização propagado pela República. A presença do edifício que abrigaria o Grupo Escolar em Patos de Minas ao mesmo tempo em que representaria o desejoso progresso era a materialização das ações em prol da instrução pública. É característica aos anos que compõem as décadas finais do século XIX a defesa de lugares apropriados e destinados à educação das crianças, passando os políticos e profissionais "a advogar a necessidade de espaços edificados expressamente pelo serviço escolar" (SOUZA, 1998, p. 122). A esses espaços caberia arcar com a finalidade social e moral da instrução pública primária, era a casa "[...] o povo se vae habilitar para as suas grandes emprezas na vida se afastar do cahos onde a ignorancia e o crime se anivelam". (O TRABALHO, 1908, 
n. 62, p. 01-02). A "elite" patense por iniciativa própria procurava banir a ignorância e insistentemente defendiam que:

O problema da instrucção publica, é, no primeiro plano das plataformas dos governos intelligentes a principal ideia que a deve empolgar, e a razão ahi está frizante na observação dos factos tanto maior é o desenvolvimento do povo quanto maior é o número de suas escolas. (O TRABALHO, 1908, n. 62, p. 01-02)

Patos de Minas estava continuamente na defesa de uma boa instrução, pois, a falta dela seria considerado pelo contexto local o único mecanismo capaz de dar explicações para o atraso da sociedade brasileira. Fato que pode ser claramente observado neste discurso:

Instrua-se o povo, prepare-o convenientemente e veremos a situação geral do Paiz marchar a contendo dos maiores heréticos contra nossa felicidade de povo magnânimo, vivendo actualmente na miséria e repousando sobre os maiores thesouros com que a sabia natureza nos aprouve aquinhoar [...].(O TRABALHO, 1908, n. 62 , p. 01-02)

A "elite" local a partir da necessidade de organização escolar ligada ao processo civilizatório, tendo como maior representante o Grupo Escolar, não mediu esforços no sentido de dotar a cidade com essa instituição e oferecer maiores oportunidades de acesso na atividade escolarizada. A educação era vista como instrumento capaz de amalgamar os ideais morais tão necessários para a (re) construção da nação brasileira. Essa concepção foi veiculada pela imprensa de Patos de Minas que defendia a instrução como:

Alicerce da paz, da concórdia e do progresso. Sem ella, digamos
com franqueza, assemelhamo-nos aos brutos, estamos prontos a
commetter toda sorte de arbitrariedades, toda sorte de crimes,
mesmo os mais bárbaros, os crimes mais repugnantes. Devemos,
portanto instruirmo-nos; devemos educar os nossos filhos, para
que, mais tarde, eles não nos dêm desgostos, tornando-se
criminosos. Devemos mandal-os à eschola, porque, 'a eschola é a
miniatura da sociedade', como disse alguém. Nella entrando, a
creança penetra o recinto em que receberá as primeiras noções dos
deveres recíprocos, que constituem o trato social. Esses deveres,
embora tantos e de tão varias espécies, são quase todos esboçados
e exemplicados na eschola. 'A eschola é o pequeno scenario, onde
se ensaiam as exibições da vida'. Devemos procurar para nossos
filhos um professor ilustrado [...] devemos, sim, é um de nossos
mais sagrados deveres o tratamos da educação de nossos filhos. O 
seu futuro depende da instrucção que Ihes dermos; si ella for bôa, eles serão bons; si for má forçosamente serão maus. (COMMERCIO, n. 32,1911 , p. 01 )

A escola seria passagem obrigatória para formação dos bons costumes e do caráter, não caminhar por essa passagem representaria a degeneração do espírito. Pode-se aquilatar essa afirmação aos pressupostos da República Velha, isto é, o fortalecimento da educação na concepção humanitária e a crença de incapacidade que pesava aos ombros do indivíduo desprovido de instrução. Os anos iniciais da Proclamação da República tornaram-se uma "cruzada" para organização da instrução pública elementar já que parecia incompatível a coexistir "grande povo" sem um processo sério de educação.

Baseado nessas convicções pode-se concluir que educar significa "formar, desenvolver e dirigir aptidões individuais, melhorando-as, dando-lhes possibilidades novas, adaptando-as às necessidades da época, às exigências do momento e do meio". (COMMERCIO, n. 32, 1911, p. 24)

Esses pressupostos podem ser identificados em matéria do Jornal Cidade de Patos:

Nos parece ser o problema mais palpitante, de maior relevo e que deve maior carinho merecer dos poderes públicos. Em um paiz como o nosso, em que o analphabetismo domina mais de dois terços da população, é um erro procurar-se proteger as industrias, a lavoura, o commercio, as artes, etc. sem primeiro cuidar-se da instrucção primaria da individualidade. Já não nos referimos a instrucção secundaria, mas a primaria. O que vale distribuir-se arados e outras machinas a pessoas analphabetas? O que acontece é, que ellas materialmente pegam destes instrumentos e não sabendo ler as instrucções para usal-as, o resultado primeiro é negativo e ellas abandonam e voltam a rotina que Ihes é habitual de d'ahi, não se lhes arranca mais. O que vale facilitar-se a introducção de animaes de raça quando os creadores na sua maioria não sabe fazer uma seleção de cruzamento, etc? o povo não conhece tarifas, não conhece leis nem os seus direitos, quer políticos, quer cívicos. Os expertos explora a vontade. Podem fazer as melhores leis, que ellas serão burladas, porque a maioria da população não entende e não as conhece, por não saber ler, siquer. (CIDADE DE PATOS, 1916 , n. 61, p. 01)

Estava manifesta a opinião de alguns intelectuais da "elite" patense em relação ao processo educacional. A imprensa de Patos de Minas muito argumentava para mobilização educacional, mas também não se furtava de 
relatar a frustração pela falta de um Grupo Escolar na cidade para que de fato a instrução primária pudesse ser consolidada, visto que, em 1915 o Grupo era apenas um decreto. Em termos de ações concretas, existia um projeto que autorizava o Executivo o dispêndio de numerários financeiros para colaborar com a construção do prédio, isso em 1913, conforme lavrado em Ata da Câmara:

O senhor Agenor Maciel, por parte da Comissão de Redacção apresentou o parecer que recebeu o numero onze, offerecendo a redacção final do projecto numero três, do senhor Noé Ferreira da Silva, auctorizando o Agente Executivo a dispender ate vinte contos de réis (20:000\$000), para auxiliar a construcção de um prédio destinado a um grupo escolar n'esta cidade, ficando-lhe aberto o necessário credito, podendo empregar as rendas acumuladas por leis anteriores, destinadas as obras publicas, revogadas as disposições em contrario. O mesmo senhor pediu a palavra e requereu urgência para que fosse immediatamente approvada a redacção final d'este projeto, sendo pela camara concedida a urgência requerida, o senhor Presidente pôs em discussão, não havendo que sobre a mesma pedisse a palavra, pôs a votos, sendo unanememente approvada. Lavre-se o autographo. (ATA DA OITAVA SESSÃO ORDINÁRIA DA CÂMARA, 1913, s/d)

Todas as discussões e ações convergiram somente para a instalação do estabelecimento escolar que fora previamente denominado de "Grupo Escolar de Patos". Decorridos os anos, a inauguração do Grupo Escolar em 04 de junho de 1917 representava a materialidade dos ideais de civilidade, modernidade e progresso. Essa data foi marcada por comemorações, para as famílias representou um dia festivo já para as autoridades locais responsáveis por presidir a cerimônia de instalação os discursos tinham tom de felicitações, vejamos:

Tomando a palavra o inspector municipal, expoz aos presentes o fim daquela sessão, a qual era a instalação do grupo escolar, e detendose em outras considerações relativas ao acto se se ia realisar, conclui-o por felicitar, em nome do governo, à população de Patos, pela acquisição que acabava de ser effectivada, para beneficio da instrucção neste municipio. Concedida a palavra aos oradores inscriptos [...] os quaes em termos cheios de elevação e em que se traduzia o jubilo e o reconhecimento do povo pelo melhoramento que the era concedido, muito concorreram para o brilhantismo do acto, no qual se acha representada a população da cidade, com o comparecimento de numerosas famílias. Para maior realce da solenidade, compareceram as duas corporações musicaes que executaram alternadamente, marchas festivas. (MONTEIRO, Termo de Instalação, 1917, s/p) 
O inspetor municipal, Maurício Pottier Monteiro, na solenidade de inauguração sugeriu a mudança de nome da instituição para "Marcolino de Barros" $^{8}$. Fazendo o uso da palavra o inspetor declarou:

Por solicitação e traduzindo o pensamento de vários amigos, salientou o ardor com que se havia empenhado o Dr. Marcolino de Barros para a realização desse desejo, há muito alimentado pelo povo e acabava de se concretisar, e lançou a ideia de ser dirigida ao governo do Estado, uma representação em que se solicite seja dada a denominação - Marcolino de Barros - a este grupo escolar, tendo como testemunho de reconhecimento e para que fique ligada a esta instituição a benemerência de seu nome (MONTEIRO, Termo de Instalação, 1917, s/p).

O Grupo Escolar na maioria das vezes recebia o nome daquele que muito trabalhava em prol da instrução pública, como aconteceu com o Dr. Marcolino Ferreira de Barros. "Instituía-se a figura do 'patrono', personalidade a ser enaltecida e cultuada por professores, alunos e a sociedade especialmente em datas de comemoração do aniversário da escola" (SOUZA, 1998, p. 134) Pode-se afirmar que:

A escola primária, dever do Estado e direito do cidadão, transformase em uma dádiva; não é apresentada à população como decorrência de uma política social, mas como resultado do concurso de um 'honorável cidadão'. Como tais homens pertenciam à oligarquia econômica e política ficava reafirmada a legitimidade a figura do patrono e da República (SOUZA, 1998, p. 134).

Tendo em vista, tão grandes feitos para a cidade patense parecia justo que o Grupo Escolar recebesse o nome do Dr. Marcolino de Barros, decorridos dois anos foi deferido o pedido e em 1919, o estabelecimento de instrução pública passou a denominar "Grupo Escolar Marcolino de Barros". Em relação à homenagem prestada ao Dr. Marcolino como sendo o patrono para Grupo Escolar, o jornal "Cidade de Patos" registrou a seguinte nota:

\footnotetext{
8 Segundo consta em Fonseca (1974, p. 217) a trajetória de militância política de Marcolino Ferreira de Barros refere-se ao governo do município entre 1914/1918 e 1926/1930 períodos marcados por um surto progressista, materializado na construção do grupo escolar, na instalação do serviço de água, na construção de estradas e pontes, em melhorias no centro urbano, entre outros melhoramentos. Faleceu em 1932, sem conhecer o prédio definitivo do grupo escolar entregue em 1933.
} 
[...] testemunho de reconhecimento, e do alto valor em que são tidos os seus esforços pelo progresso do município. É uma homenagem esta, em que se faz abstracção do seu valor político, e real e merecido destaque, para nelle se encarar com maior saliência o incansável benemérito desta terra, que tanto deve hoje. É, pois, uma homenagem filha de sentimentos nobres e legítimos, e a qual todos os habitantes de Patos vão prestar o seu concurso, sincero expontaneo e justiceiro! (CIDADE DE PATOS, n. 119, 1917, p. 1)

A inscrição "Grupo Escolar" estampada em lugar de destaque na fachada da edificação, no caso específico de Patos de Minas, representava por um lado a identidade dada à instituição digna por ministrar a instrução pública da cidade e por outro lado testemunhava e atestava o empenho de quem havia despendido esforços para materialização do ato, seria uma forma de reconhecimento e agradecimento. Vale a pena conferir, no artigo que se segue, os comentários do articulista em relação à inauguração do Grupo Escolar como afirmação de um novo padrão de comportamento embasado na disciplina e na boa moral.

O acontecimento mais palpitante da hebdomada que vem de decorrer foi para Patos a installação do seu Grupo Escolar. E realmente, deve ser assignalado entre os factos da chronica da nascente cidade, como um dos mais promissores passos para o seu desenvolvimento intellectual e material, e como um dos melhores benefícios para a sua população[...].Um Grupo Escolar, rigorosamente constituído, preenchendo cabalmente os seus fins, não é uma acquisição secundaria e vulgar. Tem alguma cousa de mais significativamente elevado, do que os marcos de adeantamento que apenas satisfazem o goso e a commodidade. É um núcleo de trabalho, de aperfeiçoamento, em que as intelligencias se dilatam, a vontade e o caracter se educam, as faculdades se manifestam e aperfeiçoam, abrindo à infância um futuro até então desconhecido, e campos mais vastos e accessíveis para a applicação da actividade. A evolução dos caracteres e das intelligencias, é que succedem então os artefactos do progresso ela eclosão das necessidades e das aspirações, que vão surgindo progressivamente. Ao lado de cada escola de letras, deveria existir um aprendizado do trabalho. Mas este, surge por si mesmo, quando o menino sentindo-se capaz de aspirações, tem a ideia do dever, e comprehende que necessita do trabalho, para poder vencer na vida.

A população de Patos deve pois, rejubilar-se com o acontecimeno que se concretisou na installação do Grupo Escolar, iniciado sob tão bons auspícios, e cercado das melhores garantias para fecundos e proveitosos resultados (CIDADE DE PATOS, n. 199, 1917, p. 1) 
Realiza-se com o Grupo Escolar o projeto político local de promover a modernização dos serviços públicos, de forma especial a instrução pública na cidade. Os espaços do Grupo Escolar construído em Patos de Minas pareciam atender bem do ponto de vista administrativo-pedagógico as necessidades advindas do ensino graduado, o Grupo era fisicamente composto por: um salão central, seis salas de aula, um cômodo destinado ao toalete dos professores, seis sanitários, sendo três para cada sexo, dois pátios amplos para recreio e exercícios físicos e uma sala para a biblioteca, já as grandes janelas que ocupavam a fachada do estabelecimento e os alpendres eram responsáveis por arejar o ambiente. A imponência do prédio afirmava sua identidade e finalidade de servir à instrução pública.

Apesar de não termos a exatidão do projeto arquitetônico do primeiro prédio do Grupo Escolar, decorridos apenas 04 anos de sua inauguração, o prédio já dava sinal de serem necessários alguns reparos em sua estrutura, registrados por Honório Guimarães, na ocasião inspetor regional de ensino, o termo de visita atestava:

Prédio escolar: precisa de reparos urgentes, que foram orçados e cuja execução, devidamente autorizada vai ter lugar para estes dias. Pateos de recreio: o Diretor pedirá autorização para mandar proceder a capina do terreno escolar, informando à secretaria a importância a dispender. Depósitos de agua: as caixas que acumulam as reservas d'agua são insuficientes para as descargas necessárias ao bom funcionamento das instalações sanitárias (GUIMARAES, Termo de Visita, 1921).

Esses reparos estruturais no Grupo Escolar foram solucionados, pois decorridos três anos consta no Termo de visita do inspetor regional Joaquim Gasparino P. de Magalhães que:

Ao revistar as condições do prédio, acomodações, instalações sanitárias e todo o mobiliário escolar, constatei que tudo se acha em bom estado de conservação, verificando também que o prédio e todas as suas dependências offerecem a segurança de hyggiene e conforto exigida pelo regulamento de instrucção publica do Estado (MAGALHAES, Termo de Visita, 1924).

Parecia ser rotina da edificação que abrigava o Grupo Escolar a necessidade de reparos, no período de 05 a 26 de abril de 1926 o Grupo recebeu 
visita de inspeção técnica realizada por Salatiel Rodrigues de Melo e de acordo com o Termo de Visita lavrado percebe-se que as condições físicas do prédio estavam novamente sinalizando a necessidade de reformas:

\begin{abstract}
Não está bem conservado. Paredes exteriores denegridas pela acção do tempo e as interiores necessitadas de limpeza, assim como o soalho tem alguns defeitos. Os alpendres também precisam de reparos [...]. Há dois pateos amplos para exercicos physicos e recreio dos alummos, sendo lastimável o estado dos muros, que estão ainda em alvenaria de tijolos, sem rebouco e caiação (MELO, Termo de Visita, 1926).
\end{abstract}

No ano subsequente tem-se o apelo do inspetor municipal, Antônio Dias Maciel, que após vistoria no prédio pronunciou: "Deixo exarado neste termo de visita um apelo aos poderes competentes para que sejam sanadas as faltas que se me deparam: o prédio em que funciona o grupo necessita de uma limpeza geral e concertos inadiáveis" (MACIEL, Termo de Visita, 1927).

Apesar dos registros e solicitações em relação aos reparos que se faziam necessários no edifício do Grupo Escolar, não constatamos nos documentos analisados, as providências que foram tomadas, talvez essa lacuna de providência se deve ao fato de ser um prédio provisório, pois a "elite" local estava envidando esforços para se construir um Grupo Escolar que fosse realmente condizente com a importância de suas atribuições. O novo prédio e definitivo do Grupo Escolar Marcolino de Barros foi entregue para a população em 1933. A "concretização da construção definitiva do prédio se deve a esforços de Olegário Maciel que a época da construção era Presidente do Estado" (MELLO, 2008, p. 193). Esse imponente e majestoso estabelecimento de ensino foi construído na região central da cidade e ocupava uma extensa área. Sua nova estrutura em forma de " $U$ " ocupava dois pavimentos cujo acesso se dava por escadarias. Agora era considerado pela "elite" um estabelecimento condizente com os ideários republicanos no sentido de prosseguir com projeto de formação do cidadão da República para a República.

\title{
A Instrução Pública ministrada no Grupo Escolar patense
}


Com a instituição da escola graduada no Brasil, começou-se uma maior preocupação com as práticas educacionais, visto que, os Grupos Escolares denotava uma nova organização tanto administrativa quanto pedagógica para o funcionamento da escola primária. Nessa perspectiva, foi agregado maior valorização ao método intuitivo posto que se apresentasse com condições para renovar o ensino nos anos iniciais da República. Esse método:

Enquanto expressão de tendências mais modernas no campo educacional o método pressupunha uma versão científica da pedagogia, possibilitava a modernização da escola independente das questões financeiras e políticas pressupostas na adoção, por exemplo, da escola graduada [...]. (SOUZA, 1998, P. 1969).

No caso específico de Patos de Minas, o inspetor Honorio Guimarães pedia pela utilização do método intuitivo, pois possibilitaria através das atividades desenvolvidas a construção da regra em lugar da decoração das regras advindas dos volumosos compêndios. $O$ inspetor assim argumentava:

\begin{abstract}
Abolidos os compêndios que são de leitura para os estudantes, temos de substituir aquelle systhema de decoração pelo emprego do methodo intuitivo e empírico, pondo as questões muito claras para os alumnos, que aprenderão a solucionl-as livremente, com os elementos de saber adquiridos progressivamente, cada um exprimindo por suas próprias palavras. Este systhema deve ser plantado nas classes de primeiro anno adeantado, vindo a ser arvore frondosa nas do $3^{\circ}$ e $4^{\circ}$ anno; porque parece ter sido esse o objetivo pedagógico do reformador. Não serão dadas regras logo de começo e até não deverão ser dadas, mas o próprio alumno formulará a sua regra, a lei segundo a qual ele praticará o saber adquirido (GUIMARAES, Termo de Visita, 1921).
\end{abstract}

Como se tratava de uma nova forma de ensinar, a tarefa de "como ensinar o professor a utilizar" com maior eficiência o método intuitivo recaía às vezes aos ombros dos inspetores escolares, que quando em visita orientava os professores e em alguns momentos assumiam também o papel de professor, conforme consta no Termo de visita do inspetor Honorio Guimarães, em fevereiro de 1921:

Expuz aos professores o meu ponto de vista na pratica do ensino das diversas disciplinas do Programma, conforme a orientação pedagógica que conheci na Escola Normal modelo principalmente 
no ensino de Língua Pátria [...]. Para fazer-me comprehendido melhor, lecionei durante a quinzena nos dois turnos, de tarde o $3^{\circ}$ anno e de manhã o $4^{\circ}$ anno, tendo prestado assistência também as classes de $1^{\circ}$ e $2^{\circ}$ anno. Expliquei como se poderá harmonisar o horário do dia e o seu registro no Diario de Classe, com o preceito do art. 304 do Regulamento; justifiquei o êxito da associação das licções, si precedidas do preparo antecipado dellas pelo professor. Os exercícios práticos deverão ser dados diariamente, como subsidio para o preparo da licção pelo alumno. Si o ensino é resultado do trabalho do mestre e do alumno, não se comprehende que aquelle trabalhe e este não. A reprodução, pelo alumno, da matéria ensinada, proporciona-lhe a contigencia de preparar, elle próprio os compêndios manuscriptos em que estuda e consulta (GUIMARAES, Termo de Visita, 1921).

Diante das orientações do inspetor e decorridos alguns meses de aplicabilidade do método intuitivo os resultados começaram a aparecer, "[...] a impressão geral que tive do trabalho foi a melhor possível, porque notei o esforço do diretor e das professoras, no cumprimento das minhas instrucções aqui deixadas na minha última visita [...]". (GUIMARAES, Termo de Visita, 1921). Tendo em vista os resultados positivos que estavam sendo colhidos, o inspetor prosseguia com as orientações de forma bastante minuciosa.

No correr da minha inspecção julguei de utilidade fazer as seguintes recomendações: insistir com os alumnos a fim de emitirem as palavras com voz alta e clara; corrigir-lhes os defeitos de prosódia que vêm das rr gutturaes e das ss apagadas que não confirmam os pluraes das palavras pronunciadas; alternar, com frequência a posição dos minuendos nas operações de subtracção, pois a creança, habituada a tomar sempre como minuando o numero que está por cima não se dá ao trabalho de indagar qual o numero maior, corrigir com exigência a maneira de pegar a pena e não consentir que deitem a cabeça sobre o braço ou sobre o papel; exigir que a creança faça, em voz alta e clara, as suas operações no quadro negro. Estas observações são extensivas a todas as classes do Grupo. Nas classes de Arithmetica redigir os problemas de modo a provocar o raciocínio em grau quanto possível, os exercícios de redação, deixando a creança escrever livremente o trecho original de sua invenção para depois corrigir-Ihe os erros; cobrar com insistência as pausas e colocação dos signaes orthographicos. Faço estas recomendações que aqui ficam registradas, esperando que sejam seguidas com o máximo escrúpulo, tornando assim o mais efficaz possível o nosso esforço na luta contra o analfabetismo (MAGALHAES, Termo de Visita, 1024).

Quanto ao método a ser utilizado estava claro, no entanto para se empregar um método é preciso saber o que deveria ser ensinando, suscitando, 
porém, a questão do programa de ensino, questão que ganha relevância, pois "era o instrumento pelo qual a escola primária realizaria as finalidades atribuídas a ela" (SOUZA, 1998, p. 171). Não é nosso intuito nesse trabalho analisar proficuamente o programa de ensino, nos limitamos apenas de passagem a explicitar que as matérias: Leitura, Escrita, Língua Pátria, Aritmética, Geografia, História do Brasil, Instrução Moral e Cívica, Geometria e Desenho, História Natural, Física, Higiene, Exercícios Físicos, Trabalhos Manuais, Música e Canto, conjugavam a abrangência de natureza científica e moral, sem laços com a doutrina cristã. O programa "prestigiava matérias cujo princípio era o da formação global do indivíduo, abrangendo todo o conhecimento humano" (SOUZA, 1998, p. 171). Através do Decreto de 30 de setembro de 1906, houve a divisão do tempo escolar, bem como a indicação de conteúdos disciplinares e atividades que seriam práticas. Entendemos que a finalidade de se estabelecer um programa comum para todos os Grupos Escolares era oferecer formação cultural comum para todo o cidadão de uma mesma pátria. Em Patos de Minas, as orientações referentes ao programa de ensino foram em 1917 repassadas para o diretor e professores do Grupo Escolar Marcolino de Barros pelo inspetor regional, Orlando Ferreira, as instruções, de acordo com o inspetor, "facilitariam a uniformidade de orientação do ensino". Tal atitude visava à consistência de uma cultura escolarizada que tornou marca característica dos Grupos Escolares e da Instrução Primária nos decênios iniciais da República, Patos de Minas seguiu à regra.

Outro aspecto que compunha o rol de preocupações dos inspetores escolares se refere à ordem e à disciplina como elementos indispensáveis para uma cultura escolarizada que ainda estava em formação. Acerca dessa questão, encontramos as seguintes pontuações do inspetor Honorio Guimarães em 1921:

A disciplina, soffrendo uma modificação profunda, melhorou sensivelmente: a ordem é boa e o ambiente escolar, no seu conjuncto tornou-se mais agradável [...] no anno que vem, uma acção ainda mais enérgica - a partir do primeiro dia - será desenvolvida em favor da disciplina e especialmente do silencio em forma e na sala. O silencio é a alma da ordem. Violada esta regra disciplinar, tudo está perdido. Como tenho praticado em varias escolas e em grupo especialmente, suggeri ao Director a conveniência de se adoptar nesta casa a instrucção militar, com o que elle concordou. A disciplina militar, como meio de cooperar na 
disciplina gera,desenvolvendo nas creanças o espírito de associação produz resultados magníficos em classe e fora della (GUIMARAES, Termo de Visita, 1921).

Havia preocupação em corrigir os comportamentos considerados inadequados dentro e fora da sala de aula para incutir-lhes os bons costumes e não prejudicar a ordem escolar. Tais comportamentos disciplinares adequados e tidos como propulsor da ordem e da moral deveriam ser instituídos nos Grupos Escolares sem fazer o uso de castigos físicos, mas através do conselho, da persuasão, numa relação de afeição entre professor e aluno. A tarefa de instruir quanto a disciplina e a ordem no Grupo Escolar de Patos de Minas ficou a cargo do inspetor Honório Guimarães que em 1921 orientou o diretor na elaboração do regimento interno que deveriam contemplar as regras disciplinares enumeradas pelo inspetor:

1. Antes do recreio e depois do recreio, nenhum alumno do $2^{\circ}$ ao $4^{\circ}$ anno, salvo motivo especial, pode sahir da classe mais de uma vez. 2.Desde que entram o portão, nenhum alumno pode sahir, mesmo antes do começo das aulas, sem ordem do Director, si elle ainda não estiver na casa, sem ordem da professora da classe; em ultimo caso, sem ordem da servente. 3. Em classe, nenhum alumno abandonar a sua carteira sem permissão da mestra. Para falar a ella, o alumno erguerá o signal com o braço direito, mão aberta ara a direcção do tecto. Dois ou mais alumnos não poderão falar ao mesmo tempo. 4. Durante o horário, nenhum alumno sairá da classe sem licença da professora e do grupo sem a do Director. 5. Durante o recreio nenhum alumno penetrará na sala que serve de Directoria, sem permissão da servente ou de seu professor ou do Director, do mesmo modo não penetrará nas salas de aula. 6. Nas classes haverá o silencio indispensável, que as professoras exigirão, afim de que a ordem collabore no êxito do ensino que ministram. 7. Ouvindo o signal [ilegível] cada alumno deve fazer silencio inmediatamente e ganhar o seu lugar na forma ou sahir para o recreio e ao voltar delle. 8. É prohibida expressamente a conversa na forma. [...] 11. O alumno que traçar em quaisquer paredes do prédio escolar, palavras reputadas, obcenas, será punido severamente. 12. A servente é auxiliar da disciplina, devendo portanto, ter força moral sobre os alumnos; reclamando do Director e professores auctoridade para o conseguir [...] 16. Director e professores não perderão ensejo de censurar, corrigir e aconselhar os alumnos, todos os dias, sobre a conducta delles na escola, na rua e em casa, tendo em vista que o dever do mestre não é somente instruir, mas principalmente educar. 17. Ao debandar, os alumnos são obrigados a deixar a frente do prédio com a indispensável compostura (GUIMARAES, Termo de Visita, 1921). 
Em visita realizada em 1924 pelo inspetor Joaquim Gasparino P. de Magalhães a ordem e a disciplina no estabelecimento foram elogiadas, registrou o inspetor: Quanto à ordem, disciplina e hyggiene que encontrei postas em pratica neste estabelecimento são mais que satisfatórias, e devereis continuar na cultura desses preceitos, encarando-os como base essencial de uma casa de ensino. ${ }^{9}$

Nota-se pelos registros dos inspetores escolares a transformação que a escola vinha sendo submetida nos decênios iniciais do século $X X$, tanto no sentido de possibilitar o atendimento de um número maior de alunos quanto ser um mecanismo de transformação cultural dessa população. O Grupo Escolar de Patos de Minas procurava cumprir as orientações dos inspetores escolares, elogios e atestado da seriedade do trabalho desenvolvido nesse estabelecimento permeavam alguns Termos de visita, logo no primeiro ano subsequente à instalação do Grupo foi declarado que:

Todas as classes mostram geral desenvolvimento em todas as matérias primárias do programma, existe no grupo muito boa ordem e disciplina [...] meus insignes colegas são esforçados no desempenho do espinhoso cargo de formar o caracter dos cidadãos e das futuras mães de famílias, em que Ihes foi confiada em tão boa hora em prol da mocidade [...] Deixo apenas consignado nessas singelas linhas, os meus sinceros parabens aos meus insignes colegas pelo geral desenvolvimento de seus alumnos (LANNAS, Termo de Visita, 1918).

Em 1921 o inspetor Honorio Guimarães registrou: O Director, paciente, honesto, competente e laborioso dignamente auxiliados por professoras habilitadas e cheias da melhor vontade de bem servirem nas suas cadeiras, tem conseguido elevar o nível moral e profissional deste instituto" (GUIMARAES, 1921).

Em 1927 foi registrado:

É digno de nota o conjuncto de esforços que expendem os dirigentes deste Grupo para mantel-o na autura do seu objectivo. Visitei todas as suas dependências notando o maior asseio, rígida disciplina que muito habilitam o seu Director e auxiliares - e para

\footnotetext{
9 TERMO DE VISITA, Grupo Escolar Marcolino de Barros, Patos, 15 de outubro de 1924. Inspector Regional do Ensino, Joaquim Gasparino P. de Magalhães.
} 
justiça dos que tem pela educação do Brasil de amanhã devem todos se congregar em torno dessa plêiade a esforçados para amplial-a na conclusão de sua obra. Agradavelmente impressionado retiro-me deixando nestas linhas as minhas felicitações como chefe de familia e sobre tudo como brasileiro que se orgulha de ter nascido sob o [ilegível] sagrado da nossa bandeira (Termo de Visita, 927)..$^{10}$

Pelas afirmações dos inspetores é notório que o Grupo Escolar patense trabalhava de maneira árdua no cumprimento do programa de ensino, na tarefa de instituir a disciplina e a ordem, valores tão relevantes e determinantes para o cidadão tornar-se membro da pátria republicana almejada pelos legisladores reformadores educacionais.

\section{Funcionamento do Grupo Escolar e frequência dos alunos}

Dentre as atribuições inerentes ao diretor do Grupo Escolar estava a responsabilidade de efetuar a matrícula dos alunos interessados em ingressar nesse estabelecimento. Encontra-se no Regulamento da Reforma João Pinheiro de setembro de 1906, especificamente o capítulo VII que era responsável por reger assuntos inerentes a matricula, frequência, suspensão e restabelecimento do ensino. O artigo 85 desse Regulamento estabelecia que a ausência do aluno sem causa justificada por um período de três meses seguidos, sua matrícula seria eliminada, mas "admitia-se, para legal funcionamento da escola, uma frequência bem inferior à matrícula" (MOURÃO, 1962, p. 145). Elaboramos o consolidado de frequência escolar dos anos de 1917 a 1928 do Grupo Escolar Marcolino de Barros, tomando como mês base para apuração de dados o mês de novembro de cada ano, a opção por esse mês justifica-se pelo fato de ser próximo ao encerramento das atividades escolares anuais.

\footnotetext{
10 TERMO DE VISITA, Grupo Escolar Marcolino de Barros, Patos, 8 de junho de 1927. [Assinatura do inspetor em rubrica sendo impossível a identificação].
} 


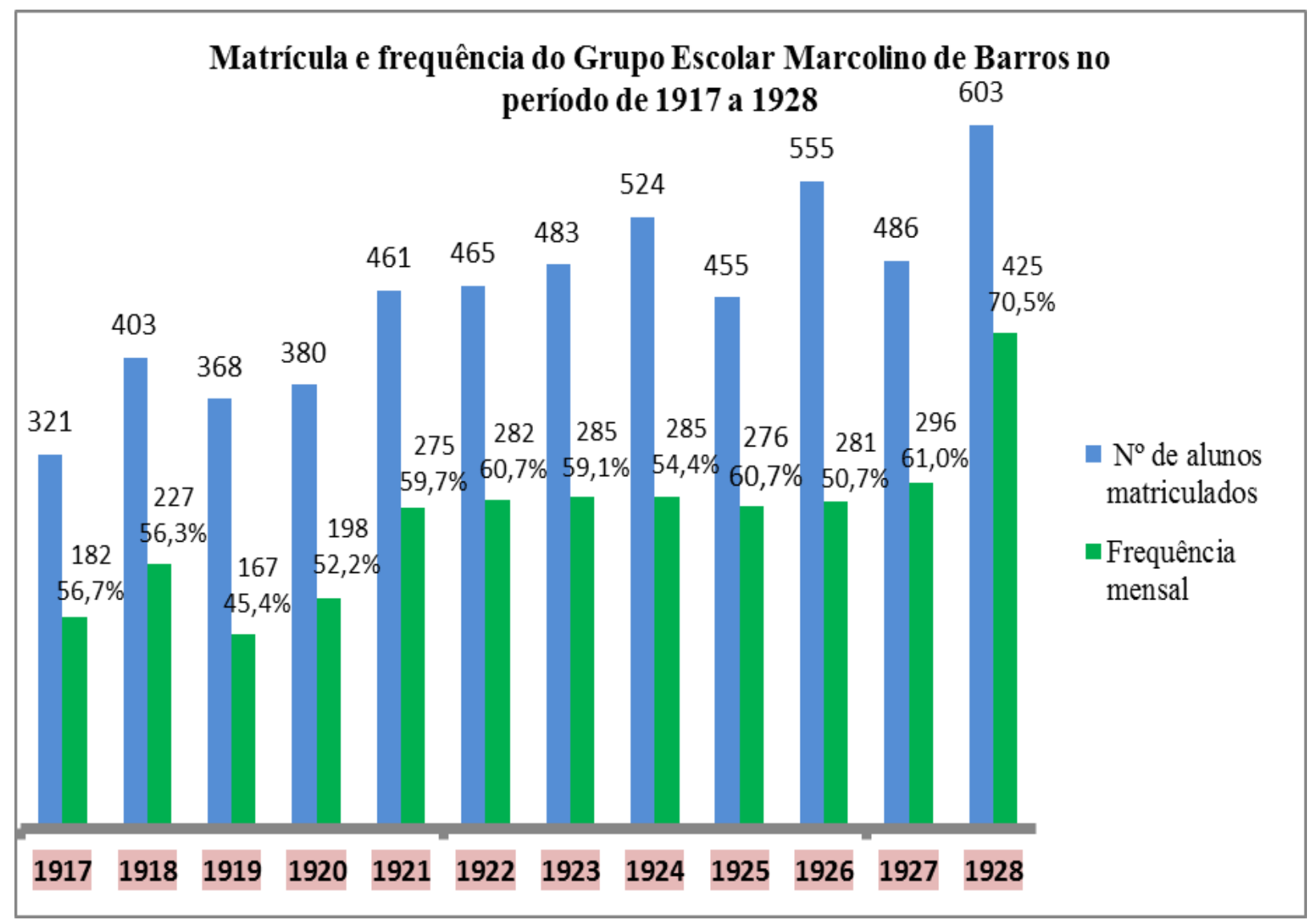

Gráfico1- Matrícula e frequência do Grupo Escolar Marcolino de Barros no período de 1917 a 1928.

Pelos dados constantes no gráfico constata-se que no ano subsequente à instalação do Grupo Escolar houve crescimento tanto de matrículas quanto da frequência mensal. Mesmo demonstrando crescimento esse foi considerado pelo inspetor ainda insuficiente e que pesava sobre os pais a responsabilidade dessa situação, afirmando que:

Terminei hoje a inspecção com a presença de 227 alunos dos 403 matriculados. A frequência devia ser maior dada a importância da cidade de Patos, incontestavelmente uma boa cidade, e o grande numero de alumnos matriculados; a culpa, porém, não é do professor deste Grupo, os quaes só merecem louvores pelo zelo e carinho com que exercem a sua espinhosa missão, e sim dos paes dos alumnos (FERREIRA, Termo de Visita, 1918).

Essa observação foi realizada pelo inspetor no mês de outubro de 1918, portanto, um mês antes do consolidado apresentado no gráfico 1 permanecendo 
inalterado o quadro até o fim das atividades desse ano. No ano de 1919 a caso estava mais caótico, houve uma diminuição no número de matrículas e a frequência foi inferior a 50\%. Diante da frequência considerada insatisfatória e por orientação do inspetor Honorio Guimarães, o diretor do Grupo "cumprindo o seu dever fez matricular no estabelecimento as crianças em idade escolar. Para isso realizar, percorreu o perímetro urbano, notificando os paes e responsáveis pelos alumnos, da obrigação em que se achavam, segundo os dispositivos da lei 800" (GUIMARAES, Termo de Visita, 1921). Essa medida foi positiva, pois:

O grupo está abarrotado de creanças, notando-se no povo uma atitude de respeito à lei, receosos da aplicação de penalidades aos seus infractores. A acção do diretor de Patos - digno por isso de todos os encômios - é um elemento probatório da exiquibilidade das disposições que crearam a obrigatoriedade do ensino. (GUIMARAES, Termo de Visita, 1921).

Em 1921 houve um aumento considerável das matrículas, bem como, da frequência escolar, fato que obrigou o Grupo Escolar a funcionar em dois turnos uma vez que dispunha somente de 06 salas de aulas para atender uma demanda de 08 classes. Nos anos subsequentes o percentual de frequência ficou na casa dos $60 \%$. O fato de a frequência não ser tão satisfatória talvez se refira ao fato de nessa época não haver ainda por parte da população valorização da "cultura escolar". A insistência por monitorar e fazer manter a frequência dos alunos nos discursos dos inspetores se deve ao peso de recair sobre a instrução ministrada no Grupo Escolar a tarefa de contribuir para a diminuição do analfabetismo, responsável por gerar muitos males a um país. Dada a insistência de conclamar as famílias para cooperarem, "é preciso que obriguemos delicada e geitosamente os paes a acompanharem com interesse a vida escolar no que se relaciona com a aprendizagem do filho" (GUIMARAES, Termo sde Visita, 1921). Esse pedido indicava duas circunstâncias, a primeira, que as famílias interessassem pela vida escolar dos filhos, em segundo momento, interessar também pelas atividades desenvolvidas no Grupo Escolar, para que pudesse dessa aliança ir vencendo paulatinamente a "resistência" em relação à educação escolarizada. O trabalho do diretor no sentido de combater a infrequência estava sendo positivo, pois no 
período compreendido entre 1921 a 1927 a frequência permaneceu praticamente estabilizada.

A frequência era um assunto que sempre compunha a pauta de trabalho dos inspetores os quais orientavam o diretor para manter contato com os pais a fim de melhorar a cada dia a situação do ensino, pois "sem a participação directa dos paes no conhecimento da vida escolar, os professores ficam desajudados e a sua acção resultará pouco eficiente" (GUIMARAES, Termo de Visita, 1921). Era preciso trazer o povo para dentro da escola e mostrar-lhes as grandes contribuições da instrução pública primária para a formação individual e coletiva da sociedade, e desse modo, melhorar significativamente a frequência e o aproveitamento dos alunos matriculados no estabelecimento oficial de ensino. Nessa incursão, pode-se afirmar que o Grupo Escolar Marcolino de Barros em parceria com os inspetores de ensino ia cada vez mais ocupando espaço na institucionalização da cultura escolarizada em Patos de Minas, chegando a conseguir 603 matrículas em 1928.

\section{Considerações finais}

O pano de fundo que compôs a tessitura desse cenário foi os anos de vigência da Primeira República. Esse movimento para se efetivar exigiu do país um processo de intensas transformações em todos os seus setores, tendo em vista, a necessidade de solidificar os ideais de ordem, progresso, modernização, democratização, combate à "epidemia do analfabetismo", reiteradamente propagados pela República. A ferramenta escolhida para ser a mola propulsora e, sobretudo, redentora, foi a educação que se encontrava envolta pelas reformas educacionais na busca pela construção de um projeto de educação popular. Nesse sentido, era possível degenerar a inércia e a incapacidade de praticar o exercício da cidadania pela massa brasileira. "A educação, portanto, mais do que qualquer outra instituição de origem humana, constitui-se no grande nivelador das condições dos homens - o volante da máquina social [...]" (MANN, 1964, p. 107). Desse modo, a idealização e a materialização da instrução pública primária, ministrada nos Grupos Escolares, estabelecimentos exclusivamente 
criados para esse fim, acreditavam os republicanos, ser o instrumento eficiente para formar o cidadão e elevar o País à condição de nação civilizada, à educação era confiada uma nobre missão, formar o homem da República para a República, o homem urbanizado, civilizado e, principalmente, o homem capaz de se adequar às novas regras de uma sociedade que buscava se alicerçar nos pilares do trabalho e da ordem pública.

Ao longo desse estudo fizemos uma análise do por que e de como ocorreu o processo de implantação da instrução pública nos moldes republicanos, dando ênfase especial para as influências exercidas sobre a "elite" que dirigia a cidade de Patos de Minas nessa época.

Para concretizar a instrução pública foi necessário adotar modelos educacionais desenvolvidos em países da Europa e América do Norte, pois, ainda não tínhamos modelos consumados de educação. Nesse cenário, os Grupos Escolares instalados na Primeira República se apresentaram como espaços ideais para materializar o projeto de civilização e educação nacional padronizada. E mais, esses Grupos representavam ainda a ruptura com o modelo de escolas isoladas e com o atraso educacional, herança imperial. Possibilitavam a reunião de várias salas de aula e professores num mesmo espaço, a utilização de programas de ensino, a otimização do tempo e do espaço escolar e, principalmente, o atendimento simultâneo a um número maior de crianças em idade escolar. Estava instituída a modernização e as políticas para controle e eficiência da educação.

Transitando da dimensão nacional para a dimensão local, nos anos iniciais do século $X X$, as discussões em torno da organização da instrução pública patense ancoravam nos pressupostos visionários da Reforma João Pinheiro, bem como, no ideário progressista e persuasivo da República. Convencidos pelas perspectivas de mudanças que poderiam ser geradas na sociedade através da instrução pública a "elite" de Patos de Minas não economizou esforços para dotar o município com esse melhoramento, tido como base para tantos outros. A ideia de instalação do Grupo Escolar na cidade transitou entre os extremos da visão frágil e incipiente que as escolas existentes apresentavam e a visão de modernidade que esses novos estabelecimentos traziam para o contexto local. Os articulistas da imprensa patense se encarregaram de disseminar esses ideais. 
Após várias empreitadas da "elite" local foi inaugurado em 1917 o Grupo Escolar de Patos de Minas, era um marco histórico e um divisor de águas para os rumos que a educação no município tomaria. Esse fato foi muito comemorado com festividades e alegrias divididas com a população, que até então, não tinha plena consciência da importância dessa instituição. Mediante análise dos documentos do Grupo Escolar pudemos constatar que em suas atividades era presente a execução dos ideais republicanos, como noções de ordem, disciplina, civismo, sempre com foco no seu maior objetivo, alfabetizar as crianças e não deixá-las sofrer dos males causados pelo analfabetismo.

Foi possível perceber também que as atividades desenvolvidas não escondiam as finalidades políticas de um projeto macro de educação voltado para a instrução, moralização e civilização. Pode-se concluir que o encaminhamento da instrução pública encontrava-se muitas vezes destinada às administrações municipais que tentavam estabelecer uma identidade própria ao ensino de acordo com as necessidades e características de cada localidade, assim ocorreu em Patos de Minas. Desse modo, se a tentativa de se compreender a História da Educação brasileira, por exemplo, por meio da legislação e das discussões educacionais (entre outros aspectos) realizadas nos estados é pertinente, não se pode esquecer que boa parte do perfil educacional dos estados não se encontra apenas nessas determinações legais, mas também na própria forma de encaminhar a educação adotada em cada município.

\section{Referências}

ADÃO, Á. ; MATOS, S. C. A imprensa periódica: memória da educação. In: TEODORO, A. (Org.). Histórias (re) construídas. São Paulo: Cortez, 2004. ARAÚJO, J. C. S.; GATTI JUNIOR, D. (Org.). Novos temas em história da educação brasileira: instituições escolares e educação na imprensa. Campinas, SP: Autores Associados; Uberlândia, MG: EDUFU, 2002. (Coleção memória da educação)

BOTTOMORE, T. B. As elites e a sociedade. Rio de Janeiro: Zahar, 1965.

CARVALHO, C. H. República e Imprensa: as influências do Positivismo na concepção de Educação do professor Honório Guimarães. Uberlândia: Edufu, 2004. 
CELLARD, A. A análise documental. In: POUPART, J. et al. A pesquisa qualitativa: enfoques epistemológicos e metodológicos. Petrópolis, Vozes, 2008.

FONSECA, G. Domínios de Pecuários e Enxadachins: História de Patos de Minas. Belo Horizonte: Ingrabras, 1974. Coleções Especiais: Autores Patenses.

LE GOFF, J. Documento e monumento. In: História e memória. Trad. Irene Ferreira et al. Campinas, Editora da Unicamp, 1996.

LOPES, E. M. T.; GALVÃO, A. M. de O. História da Educação. Rio de Janeiro: DP\&A, 2001.

MANN, H. A educação dos homens livres. Coleção Clássicos da democracia. São Paulo: IBRASA, 1964.

MELLO, O. Patos de Minas, meu bem querer. 3 ed revista, ampliada e revisada. Prefeitura Municipal de Patos de Minas, SEMED, 2008.

MOURÃO, P. K. C. O ensino em Minas Gerais no tempo da República. Belo Horizonte. Edição do Centro Regional de Pesquisas de Minas Gerais, 1962.

OLIVEIRA, M. M. Como fazer pesquisa qualitativa. Petrópolis, Vozes, 2007.

SAVIANI, D. História das ideias pedagógicas no Brasil. Campinas, SP: Autores Associados, 2007.

SOUZA, R. F. de. Templos de civilização: a implantação da escola primária graduada no Estado de São Paulo (1890-1910). São Paulo: UNESP, 1998.

VIEIRA, M. do P. de A. et al. A pesquisa em história. 3 ed. São Paulo: Ática, 1995.

\section{Sítio Eletrônico:}

http://www.histedbr.fae.unicamp.br/navegando/glossario/verb c grupo \%20esc olar.htm Acesso em 28 agos. 2012.

\section{Fontes:}

Lei no 41, de 3 de agosto de 1892, regulamentada pelo Decreto no 655, de 17 de outubro de 1893; Lei no 221 de 14 de setembro de 1889, regulamentada pelo Decreto no 1348, de 8 de janeiro de 1900 e Lei no 439, de 28 de setembro de 1906, regulamentada pelos Decretos no 1947 e no 1969.

\section{Documento}

Documento encaminhado pelo Dr. Laudelino Gomes de Almeida ao Secretário do Interior em 30 de novembro de 1907.

\section{Atas da Câmara Municipal - Patos de Minas/MG}


Ata da sexta (6a) sessão ordinária de 16 de fevereiro de 1909. Patos. Presidencia do Exmo. Senhor Dr. Olegário Maciel. Livro 05. Caixa 232, estante 15 prateleira 05.

Ata da oitava ( $8^{a}$ ) sessão ordinária da Câmara, Patos, 24 de setembro de 1913, Presidente Marcolino de Barros. Livro 07. Caixa 233, estante 15 prateleira 04.

\section{Jornais - Patos de Minas/MG}

O TRABALHO. Cidade de Patos. Anno 2, n 0 4, 9 de dezembro de 1906, p.1.

O TRABALHO, Cidade de Patos. Anno 2, no 11, 27 de janeiro de 1907, p.1.

O TRABALHO, Cidade de Patos. Anno 3, no 62, 20 de agosto de 1908, p.1-2.

O COMMERCIO, Cidade de Patos. Anno 1, no 32, 18 de junho de 1911, p. 1.

CIDADE DE PATOS, no. 61, Patos, 19 de março de 1916, p.1.

CIDADE DE PATOS. Anno 3 , no 119. Patos, 10 de junho de 1917, p.1.

\section{Termo de instalação}

TERMO DE INSTALAÇÃO, Grupo Escolar de Patos, 04 de junho de 1917. Maurício Pottier Monteiro, inspetor municipal.

\section{Termos de visita - Inspetores Escolares}

Termo de visita, Grupo Escolar Marcolino de Barros, Andalecia Gabriella Ferreira Lanas, 10 de junho de 1918.

Termo de visita, Grupo Escolar Marcolino de Barros, Inspetor Regional Orlando Ferreira, 30 de outubro de 1918.

Termo de visita, Grupo Escolar Marcolino de Barros, Patos, 16 de fevereiro de 1921. inspector regional da $15^{a}$ circunscripção, Honorio Guimaraes.

Termo de visita, Grupo Escolar Marcolino de Barros, Patos, 6 de novembro de 1921. O Regional da 15a, Honorio Guimarães.

Termo de visita, Grupo Escolar Marcolino de Barros, Patos, 15 de outubro de 1924. Joaquim Gasparino P. de Magalhães. Inspector Regional do Ensino.

Termo de visita, Grupo Escolar Marcolino de Barros, Patos, 26 de abril de 1926. Salatiel Rodrigues de Melo, Inspetor técnico.

Termo de visita, Grupo Escolar Marcolino de Barros, Patos, 27 de agosto de 1927. Antônio Dias Maciel. Inspetor Escolar Municipal.TERMO DE VISITA, Grupo Escolar Marcolino de Barros, Patos, 8 de junho de 1927. [Assinatura do inspetor em rubrica sendo impossível a identificação].

Recebido em 14 de fevereiro de 2013. Aprovado em 22 de junho de 2013. 